\title{
Estimating the referral rate for cancer genetic assessment from a systematic review of the evidence
}

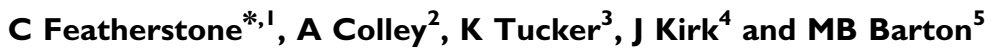 \\ 'Department of Oncology, Beatson Oncology Centre, Glasgow, GII 6NT, Scotland; ²Department of Clinical Genetics, Liverpool Hospital, Sydney, \\ Australia; ${ }^{3}$ Department of Genetics, Prince of Wales Hospital, Sydney, Australia; ${ }^{4}$ Department of Genetics, Familial Cancer Service, Westmead Hospital, \\ Sydney, Australia; ${ }^{5}$ Collaboration for Cancer Outcomes Research and Evaluation (CCORE), Liverpool Health Service, Liverpool Hospital, Sydney, Australia
}

\begin{abstract}
To estimate the optimal proportion of new patients diagnosed with cancer who require assessment and evaluation for familial cancer genetic risk, based on the best evidence available. We identified evidence of the patients who require assessment for familial genetic risk when diagnosed with cancer through extensive literature reviews and searches of guidelines. Epidemiological data on the distribution of cancer type, presence of a family history, age and other factors that influence referral for genetic assessment were identified. Decision trees were constructed to merge the evidence-based recommendations with the epidemiological data to calculate the optimal proportion of patients who should be referred. We identified 'high probability' and 'moderate probability' groups for having a genetic susceptibility. The proportion of patients diagnosed with cancer in Australia who have a high probability of having a genetic predisposition and who should be referred for genetic assessment is $1 \%$. If the moderate probability group is also assessed this proportion increases to $6 \%$. This model has identified the proportion of new patients diagnosed with cancer who should be referred for genetic assessment. This data is the first step in determining the resources required for provision of an adequate cancer genetic service.
\end{abstract}

British Journal of Cancer (2007) 96, 39I-398. doi:I0.1038/sj.bjc.6603432 www.bjcancer.com

(C) 2007 Cancer Research UK

Keywords: genetic assessment; systematic review; cancer genetics

Major advances in the understanding of the molecular basis of cancer have implications for all aspects of cancer management, including prevention, screening and treatment. Increasing knowledge about familial cancer syndromes (Lindor et al, 1998), and the ability to detect specific germline mutations in various cancer-associated genes (Fearon, 1997) means that cancer genetics should be included in standard clinical care. Estimates for which there is a familial predisposition range from 5 to $10 \%$ (Fearon, 1997; Lindor et al, 1998).

Although there are tools available to enable doctors and patients to estimate cancer risk and prognosis these cannot replace comprehensive cancer genetics clinics that offer other services to individuals who are concerned about their family history of cancer. These services include risk assessment and education, facilitation of genetic testing, pre- and post-test counselling, provision of personally tailored cancer risk management options and recommendations, and psychosocial counselling and support services (Pichert, 2004). The cost effectiveness of genetic testing is influenced by targeting genetic services to patients with a strong family history of cancer rather than screening the entire population (Griffith et al, 2004)

In Australia, the National Health and Medical Research Council (NHMRC) have published guidelines on the familial

\footnotetext{
*Correspondence: Dr C Featherstone

E-mail: Carrie.Featherstone@northglasgow.scot.nhs.uk

Received 20 April 2006; revised I5 September 2006; accepted 25 September 2006
}

aspects of cancer, recommending that patients with an aboveaverage risk contributing to the development of their cancer should be referred to a cancer genetics clinic for further assessment (NHMRC, 1999a). These 'at-risk' individuals are identified through index relatives who have been diagnosed with cancer.

The objectives of this study are to estimate the ideal proportion of new cancer cases that should be referred for genetic assessment from the best available evidence. This will identify the number of index cases overall and for each tumour type that requires assessment by a cancer genetics service. The model can be modified to incorporate new indications for referral as molecular tests are found or when appropriate prevention strategies are identified.

\section{MATERIALS AND METHODS}

\section{Optimal referral rate}

We identified from guidelines the indications for a patient diagnosed with cancer who requires referral to a cancer genetics clinic for further assessment, counselling or testing. We also identified epidemiological evidence for the different attributes associated with probability of a genetic component of cancer risk. We used Australian data wherever possible so that the result would be relevant for local service planning. The model does not include childhood or rare cancers that account for less than $1 \%$ of all cancer cases. 


\section{Indications for genetic counselling}

In this study, an indication for genetic counselling was defined as a clinical situation where a hereditary trait is likely to be the primary cause of the cancer. Identification of this trait would have an effect on the overall clinical outcome, either for the patient or their family members. For genetic counselling to be indicated there must be a diagnostic genetic test available, benefit from screening or early detection or an appropriate early intervention available to influence cancer risk and/or survival.

In Australia, the NHMRC have published guidelines on the familial aspects of cancer, recommending that patients with an above-average risk contributing to the development of their cancer should be referred to a cancer genetics clinic for further assessment (NHMRC, 1999a). Guidance on indications that can be
Table I Hierarchy of epidemiological data

\begin{tabular}{|c|c|}
\hline $\begin{array}{l}\text { Quality of } \\
\text { source }\end{array}$ & Source type \\
\hline$\alpha$ & Australian National Epidemiological data \\
\hline$\beta$ & Australian State Cancer Registry \\
\hline$\gamma$ & $\begin{array}{l}\text { Epidemiological databases from other large international groups } \\
\text { (e.g. SEER) }\end{array}$ \\
\hline $\mathrm{E}$ & Results from reports of a random sample from a population \\
\hline$\varepsilon$ & Comprehensive multi-institutional database \\
\hline Z & Comprehensive single-institutional database \\
\hline$\Theta$ & $\begin{array}{l}\text { Multi-institutional reports on selected groups (e.g. multi-institutional } \\
\text { clinical trials) }\end{array}$ \\
\hline$\lambda$ & Single-institutional reports on selected groups of cases \\
\hline
\end{tabular}

Table 2 Genetics: indications for genetic assessment: levels and sources of evidence

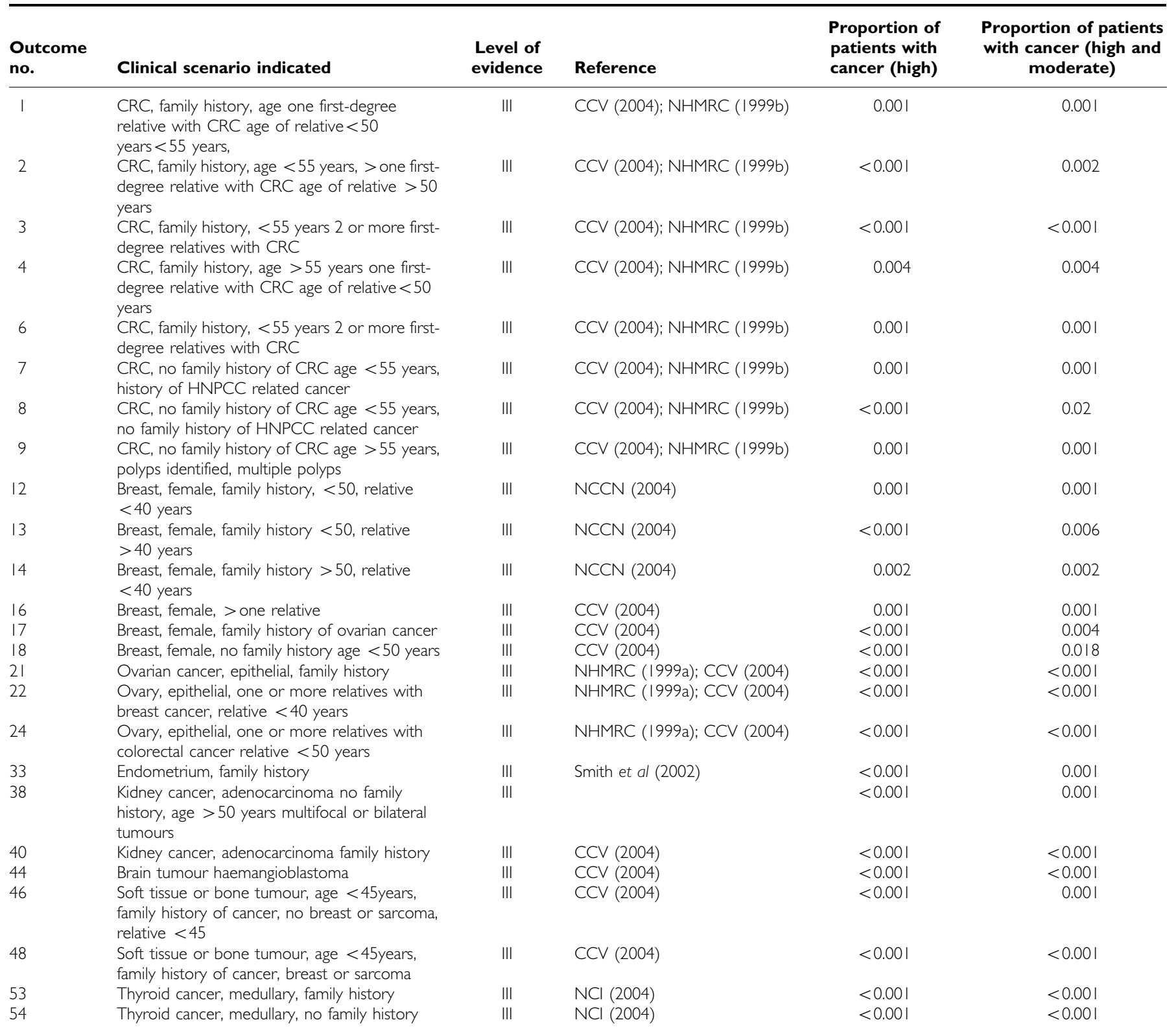

Total proportion of all patients with cancer who should be referred for genetic assessment 0.06 (6\%). * Level I, systematic review of all relevant randomised studies; level II, at least one properly conducted randomised trial; level III, well-designed randomised controlled trials without randomisation. Includes trials with pseudorandomisation or comparative studies; level IV, case series; 
Table 3 Genetics: the incidence of attributes used to define indications for referral for genetic assessment

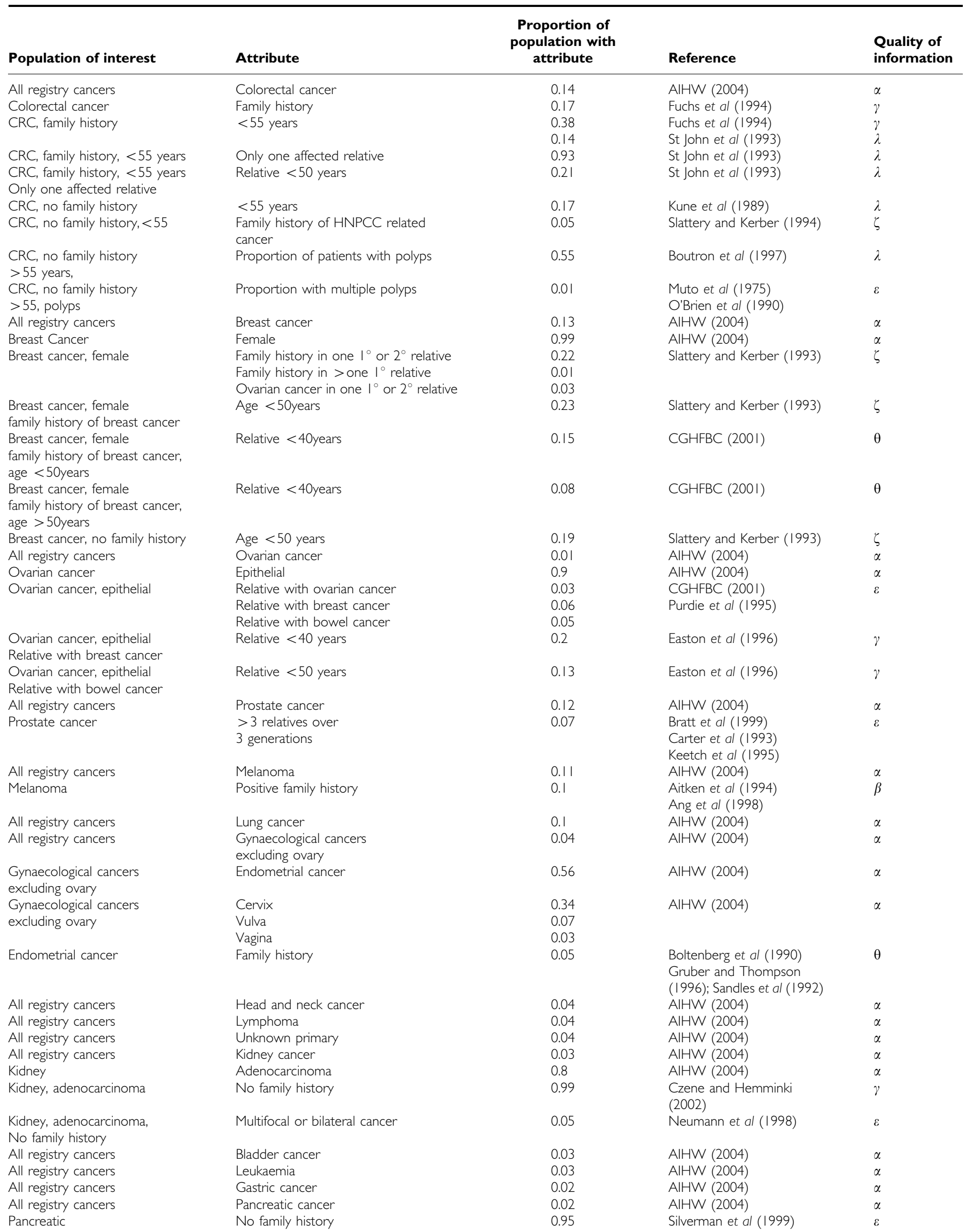


Table 3 (Continued)

\begin{tabular}{|c|c|c|c|c|}
\hline Population of interest & Attribute & $\begin{array}{l}\text { Proportion of } \\
\text { population with } \\
\text { attribute }\end{array}$ & Reference & $\begin{array}{l}\text { Quality of } \\
\text { information }\end{array}$ \\
\hline All registry cancers & Brain tumour & 0.02 & AlHW (2004) & $\alpha$ \\
\hline Brain tumour & Haemangioblastoma & 0.02 & & $\lambda$ \\
\hline All registry cancers & Soft tissue and bone & 0.01 & AlHW (2004) & $\alpha$ \\
\hline Soft tissue and bone & $<45$ years & 0.3 & AlHW (2004) & $\alpha$ \\
\hline $\begin{array}{l}\text { Soft tissue and bone, } \\
<45 \text { years }\end{array}$ & Family history of cancer & 0.05 & & \\
\hline $\begin{array}{l}\text { Soft tissue and bone } \\
<45 \text { years, family history } \\
\text { of cancer }\end{array}$ & Family history of breast or sarcoma & 0.28 & Moutou et al (1996) & $\lambda$ \\
\hline $\begin{array}{l}\text { Soft tissue and bone } \\
<45 \text { years, no family history } \\
\text { of cancer }\end{array}$ & Cancer in relative $<45$ years & 0.17 & Moutou et al (1996) & $\lambda$ \\
\hline All registry cancers & Thyroid & 0.01 & AlHW (2004) & $\alpha$ \\
\hline \multirow[t]{4}{*}{ Thyroid cancer } & Papillary & 0.72 & Hundahl et al (1998) & $\gamma$ \\
\hline & Follicular & 0.21 & & \\
\hline & Medullary & 0.05 & & \\
\hline & Anaplastic & 0.02 & & \\
\hline Medullary thyroid cancer & Familiy history & 0.26 & Moley et al (1998) & $\lambda$ \\
\hline All registry cancers & Liver cancer & 0.01 & AlHW (2004) & $\alpha$ \\
\hline All registry cancers & Oesophagus & 0.01 & AlHW (2004) & $\alpha$ \\
\hline All registry cancers & Gallbladder cancer & 0.01 & AlHW (2004) & $\alpha$ \\
\hline All registry cancers & Myeloma & 0.01 & AlHW (2004) & $\alpha$ \\
\hline All registry cancers & Testicular cancer & 0.01 & AlHW (2004) & $\alpha$ \\
\hline All registry cancers & Other & 0.01 & AlHW (2004) & $\alpha$ \\
\hline
\end{tabular}

used to help stratify the potential level of risk (high, moderate and average) are included.

Four groups were identified:

1. High probability: where the likelihood that a hereditary trait is the cause of the cancer is substantially greater than average. This group includes people whose lifetime risk for breast cancer is likely to be between 25 and $50 \%$, those who meet the modified Amsterdam criteria for Hereditary non-polyposis colorectal cancer and those at potentially high risk of developing ovarian cancer (NHMRC, 1999b).

2. Moderate probability: where the likelihood that a hereditary trait is the cause of the cancer is greater than average. This group includes people whose lifetime risk for breast cancer is likely to be between 12 and $25 \%$, and those who are likely to have a relative risk of colorectal cancer that is three- to six-fold.

3. Low probability: where the likelihood that a hereditary trait is the cause of the cancer is no higher than in the general population.

4. Research: a group where a genetic predisposition may have contributed to the development of cancer but where currently no diagnostic genetic test is available, or no benefit from screening or early detection has been determined or there is no appropriate early intervention available to influence cancer risk and/or survival.

\section{Search strategy and selection criteria}

We searched the National Guidelines Clearinghouse, Medline and the major cancer services that have guidelines on the internet for national level guidelines and guidelines issued by major institutions on the indications for referral to a familial genetics service.

There are Australian NHMRC clinical practice guidelines on familial aspects of cancer, colorectal cancer, breast cancer and melanoma. Two American sources of guidelines identified were the comprehensive Physicians Data Query (PDQ) database of the US National Comprehensive Cancer Institute (NCI), and the National Comprehensive Cancer Network (NCCN). The level of evidence that supported each recommendation for use of genetic assessment was classified using the Australian NHMRC hierarchy of levels of evidence.

The optimal genetic assessment utilisation tree was constructed using TREEAGE DATA ${ }^{\mathrm{TM}}$ software (version 3.5). Each terminal branch represents either 'referral for genetic assessment' or 'no referral for genetic assessment' as the management decision. The proportion of patients requiring referral for genetic assessment was subdivided into patients who should be categorised as having either a high or moderate probability of hereditary cancer.

Each branch of the tree signifies an attribute that affects a management decision (e.g. other family member with cancer). Above each branch is a description of the specific attribute that has led to that decision. Each number below the branch signifies the proportions of the attribute based on epidemiological data.

\section{Epidemiological data}

The source with the highest ranking was used to determine the incidence of each indication for genetic assessment. We used Australian national and state cancer registry epidemiological data wherever available to make the results of this study relevant for planning future cancer genetic services in Australia. When national data were unavailable, more specific data sets were used according to a published hierarchy. Epidemiological data were ranked according to the schema in Table 1.

\section{RESULTS}

The clinical situations for which referral for genetic assessment is recommended, and the guideline or source of evidence for the recommendation are tabulated (Tables 2 and 3). In Table 2, the outcome numbers correspond to the outcome positions in the tree (Figure 1A and B). The last column represents the incidence of each clinical indication for referral for genetic assessment as a proportion of patients diagnosed with cancer. Table 3 show the epidemiological data corresponding to each branch point, 
and the source of the data, as well as the hierarchical level of the data, obtained.

Each branch of the tree (Figure $1 \mathrm{~A}$ and $\mathrm{B}$ ) signifies an attribute that affects a management decision. Above each branch is a description of the specific attribute that has led to the treatment decision. Each number below the branch signifies the proportions of the attribute based on epidemiological data. Each terminal branch of the tree showed whether or not referral for genetic assessment was recommended for patients with those particular attributes.

\section{Outcome}

There were possible 68 'outcomes' for this tree of which 16 recommended that patients had a high probability of familial cancer and should be considered for referral to a cancer genetics service. A further nine 'outcomes' classified patients as at least moderate risk. The optimal proportion of patients diagnosed with cancer who should be referred for genetic assessment for high or moderate risk was calculated to be 0.06 , that is, $6 \%$ of all patients diagnosed with cancer in

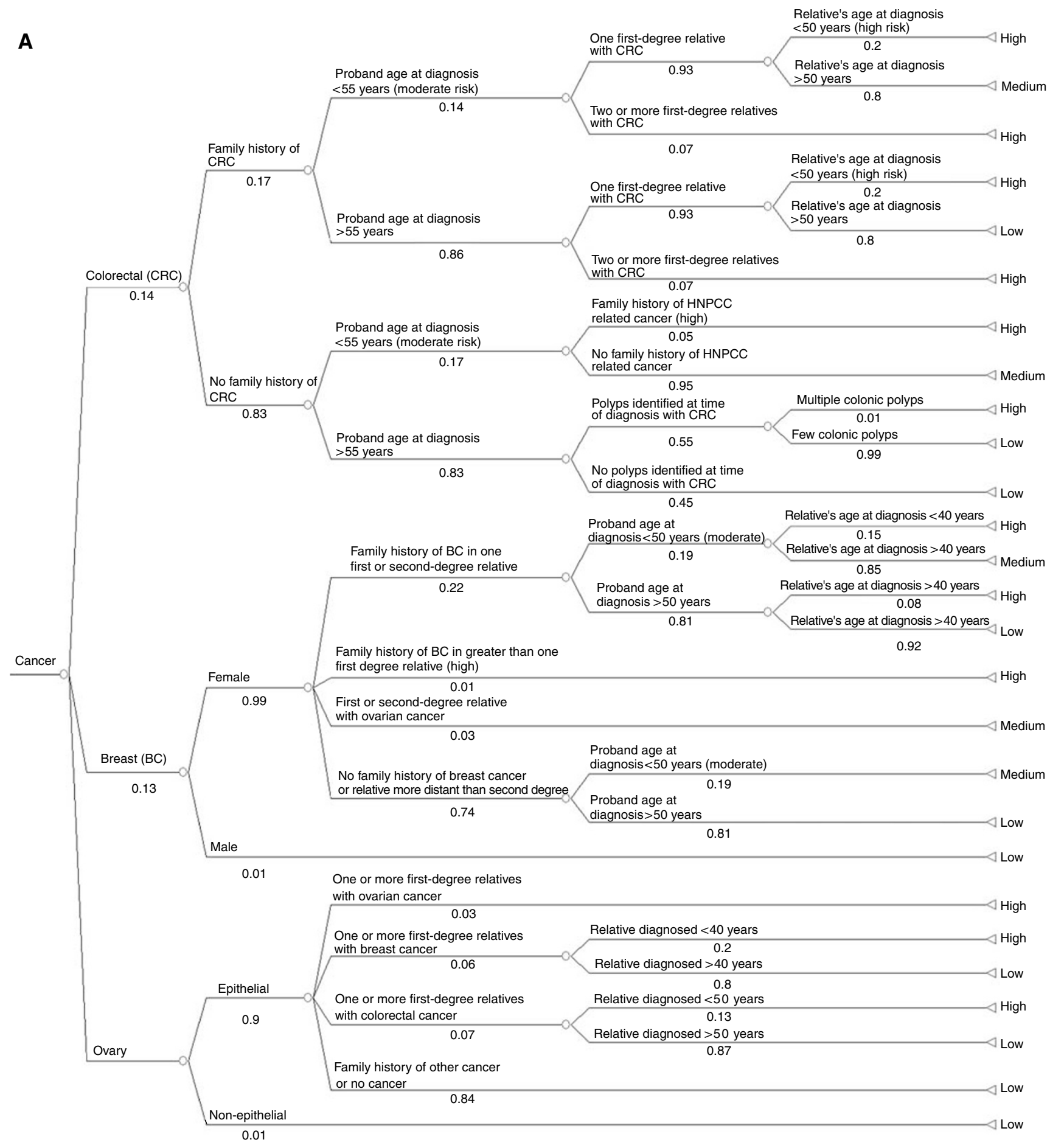

Figure I (A) Optimal referral for genetic assessment tree for colorectal, breast and ovarian cancer. (B) Optimal referral for genetic assessment tree for other cancers. 

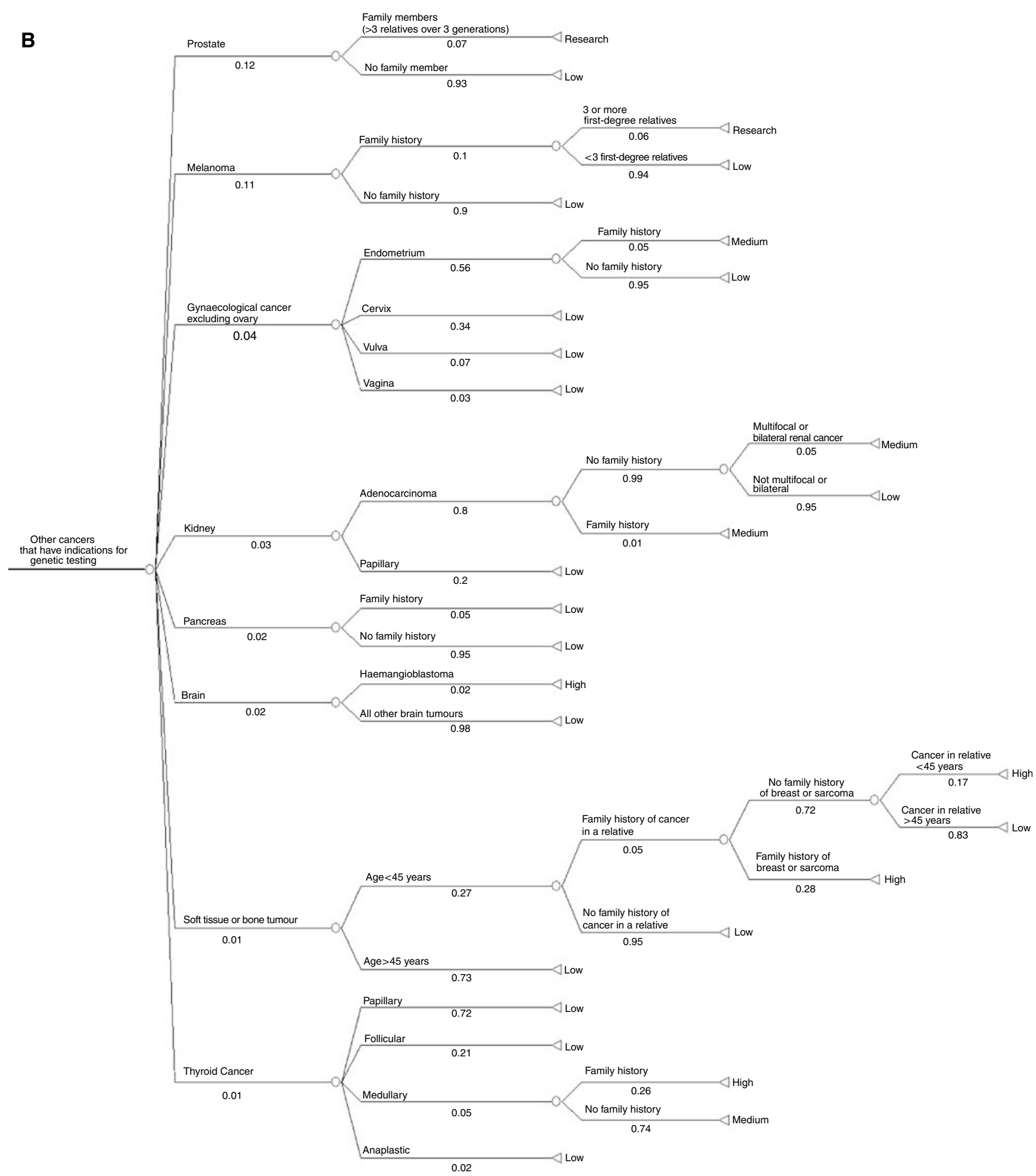

Figure I Continued

Australia should be referred for genetic assessment, based upon the best available evidence. The optimal proportion of 'highprobability' patients is $1 \%$.

Referral for cancer genetic assessment has the greatest impact for patients diagnosed with breast, colorectal and ovarian cancer. The proportion of patients diagnosed with each of these cancers who are at moderate or high probability are shown in Table 4 and Figure 1A.

Prostate cancer and melanoma fall into the group that is of research interest at present. The proportions of patients for whom genetic assessment may be eventually indicated were 7 and $1 \%$, respectively. 
Table 4 Proportion of patients who require assessment by tumour site and probability

\begin{tabular}{|c|c|c|c|c|c|c|c|}
\hline Tumour type & $\begin{array}{l}\text { Proportion of new } \\
\text { cancers in Australia }\end{array}$ & $\begin{array}{l}\text { Role for } \\
\text { genetics }\end{array}$ & High \% & $\begin{array}{c}\text { High and } \\
\text { moderate \% }\end{array}$ & Moderate \% & Low \% & Research \% \\
\hline Colorectal & 14 & Yes & 5 & 21 & 16 & 79 & \\
\hline Breast & 13 & Yes & 3 & 24 & 21 & 76 & \\
\hline Ovary & | & Yes & 5 & 5 & 0 & 95 & \\
\hline Gynae-ovary & 4 & Yes & 0 & 3 & 3 & 97 & \\
\hline Kidney & 3 & Yes & 0 & 5 & 5 & 95 & \\
\hline Brain & 2 & Yes & 2 & 2 & 0 & 100 & \\
\hline Sarcoma & 1 & Yes & I & । & 0 & 99 & \\
\hline Thyroid & i & Yes & I & 5 & 4 & 95 & \\
\hline Lung & 10 & No & 0 & 0 & 0 & 100 & \\
\hline Prostate & 12 & Yes & 0 & 0 & 7 & 93 & 7 \\
\hline Melanoma & $\mid 1$ & Yes & 0 & 0 & I & 99 & 1 \\
\hline Head and neck & 4 & No & 0 & 0 & 0 & 100 & \\
\hline Lymphoma & 4 & No & 0 & 0 & 0 & 100 & \\
\hline UK primary & 4 & No & 0 & 0 & 0 & 100 & \\
\hline Bladder & 3 & No & 0 & 0 & 0 & 100 & \\
\hline Leukaemia & 3 & No & 0 & 0 & 0 & 100 & \\
\hline Gastric & 2 & No & 0 & 0 & 0 & 100 & \\
\hline Pancreas & 2 & No & 0 & 0 & 0 & 100 & \\
\hline Liver & I & No & 0 & 0 & 0 & 100 & \\
\hline Oesophagus & I & No & 0 & 0 & 0 & 100 & \\
\hline Gallbladder & I & No & 0 & 0 & 0 & 100 & \\
\hline Myeloma & 1 & No & 0 & 0 & 0 & 100 & \\
\hline Testes & I & No & 0 & 0 & 0 & 100 & \\
\hline Other & i & No & 0 & 0 & 0 & 100 & \\
\hline
\end{tabular}

\section{DISCUSSION}

All oncology providers must be aware of the hallmarks of susceptibility to hereditary cancer in order to appropriately identify patients who might benefit from comprehensive cancer genetic counselling. Guidelines on patients who are at risk have been published by national groups (Trepanier et al, 2004) to help identify patients who require referral. Variations in referral may result from both lack of proper identification of an 'at risk' individual, clinician's nihilism in what can be achieved by screening or earlier diagnosis or variations in accessibility to these clinics (McDonald et al, 2004).

Both International and National guidelines and data were used to complete this study, and it is therefore thought to be broadly applicable. Australian cancer registry data were used for the initial proportions of each cancer type. This is recorded in the first column of Table 4 . The model can be adapted for regional services planning by incorporating data from national or local cancer registries. This study not only identifies the overall proportion of patients who might benefit from referral, but also the proportion by each cancer type. These models can be used to identify who should be considered for referral, dependent on patients' wishes and relatives who might benefit from the information obtained.

This model identifies the probability for newly diagnosed cancer patients for whom an inherited trait might be identified, and early intervention or screening may be warranted. The model does not include childhood or rare cancers such as phaeochromocytoma, although there is emerging evidence of a genetic predisposition (Neumann et al, 2002), or retinoblastoma, where all new cases should be referred for genetic assessment.

Currently in Australia only patients who are at high risk are eligible for referral. However, an optimal service should include referral of patients who are at high and moderate probability of having a genetic susceptibility, where confirmation of the family history and more detailed assessment of their probability of genetic predisposition can be determined by genetic counsellors and specialists.

Comprehensive reviews of both the psychological impact and an economic evaluation of testing and counselling have been performed (Braithwaite et al, 2004; Griffith et al, 2004). Genetic counselling for familial cancer is associated with an improvement in knowledge but does not have an adverse effect on affective outcomes.

This model identifies the optimal number requiring counselling if all index cases have a single relative who wishes to benefit from this service. It starts with the index case rather than the unaffected person concerned about their family history. For each index case data on family members is required with the number requiring referral ranging from no family members to several. This data is not currently available but may be obtainable from local databases for some of the commoner malignancies.

From the optimal proportion identified in this study, further work is required to determine the actual number of patients diagnosed with cancer in each tumour site that require access to this service, and the number of relatives that may require assessment when a genetic predisposition is identified. This can be included in the economic evaluation to help determine the value of this service to individuals, families and society. Work is also required to assess why patients may not be referred to a cancer genetic service, which is likely to include lack of awareness of the benefits of counselling and testing, lack of access to a service, patient refusal, no relatives or no family members residing in the country, and referring doctors' uncertainty as to the benefits of the service.

\section{CONCLUSIONS}

The planning of efficient cancer genetics services for a population requires a rationale estimate of its need. This model identifies the proportion of patients with cancer who may benefit from such a service by using an evidence-based approach and is the first step to appropriate planning and resourcing of cancer genetics services. Further research is required to identify both the actual proportion of the population who are referred to a cancer genetics service and also reasons why patients are currently not referred. 


\section{REFERENCES}

Aitken JF, Duffy DL, Green A, Youl P, MacLennan R, Martin NG (1994) Heterogeneity of melanoma risk in families of melanoma patients. Am J Epidemiol 140: 961 - 973

Ang CG, Kelly JW, Fritschi L, Dowling JP (1998) Characteristics of familial and non-familial melanoma in Australia. Melanoma Res 8: $459-464$

Australian Institute of Health and Welfare (2004) Incidence and mortality data. http://www.aihw.gov.au/publications

Boltenberg A, Furgyik S, Kullander S (1990) Familial cancer aggregation in cases of adenocarcinoma corpis uteri. Acta Obstet Gynecol Scand 69: $249-258$

Boutron MC, Faivre J, Quiport V, Senesse P, Michiels C (1997) Family history of colorectal tumours and implications for the adenomacarcinoma sequence:a case-control study. Gut 37: 830-834

Braithwaite D, Emery J, Walter F, Provost AT, Sutton S (2004) Psychological impact of genetic counseling for familial cancer: a systematic review and met-analysis. J Natl Cancer Inst 96(2): 122 - 133

Bratt O, Kristoffersson U, Lundgren R, Olsson H (1999) Familial and hereditary prostate cancer in Southern Sweden. A population-based case-control study. Eur J Cancer 35: 272-277

Cancer Council Victoria (2004) Victorian Family Cancer Genetics Service, http://www.accv.org.au/index.htm

Carter BS, Bova GS, Beatty TH, Steinberg GD, Childs B, Isaacs WB, Walsh PC (1993) Hereditary prostate cancer: epidemiologic and clinical features. J Urol 150: 797-802

Collaborative Group on Hormonal Factors in Breast Cancer (2001) Familial breast cancer: collaborative reanalysis of individual data from 52 epidemiological studies including 58209 women with breast cancer and 101986 without disease. Lancet 358: $1389-1399$

Czene K, Hemminki K (2002) Kidney Cancer in the Swedish Family Cancer database: familial risks and second primary malignancies. Kidney Int 61: $1813-1816$

Easton D, Matthew F, Ford D, Swerdlow A, Peto J (1996) Cancer mortality in relatives of women with ovarian cancer: the OPCS study. Int J Cancer 65: $284-294$

Fearon ER (1997) Human cancer syndromes: clues to the origin and nature of cancer. Science 278: $1043-1050$

Fuchs CS, Giovannucci EL, Colditz GA, Hunter DJ, Speizer FE, Willett WC (1994) A prospective study of family history and the risk of colorectal cancer. $N$ Engl J Med 331: $1669-1674$

Griffith GL, Edwards RT, Gray J (2004) Cancer genetics services: a systematic review of the economic evidence and issues. Br J Cancer 90(9): $1697-1793$

Gruber SB, Thompson WD (1996) A population-based study of endometrial cancer and familial risk in younger women. Cancer and Steroid Hormone Study Group. Cancer Epidemiol Biomarkers Prev 5: 411-417

Hundahl SA, Fleming ID, Fremgen AM, Menck HR (1998) A National Cancer Data Base report on 53,856 cases of thyroid carcinoma treated in the US 1985-1995. Cancer 83: 2638-2648

Keetch DW, Rice JP, Suarez BK, Catalona WJ (1995) Familial aspects of prostate cancer: a case-control study. J Urol 154: 2100-2102

Kune GA, Kune S, Watson LF (1989) The role of hereditary in the etiology of large bowel cancer:data from the Melbourne Colorectal Cancer Study. World J Surg 13: 131

Lindor NM, Greene MH, the Mayo Familial Cancer programme (1998) The Concise Handbook of Family Cancer Syndromes. JNCI 90: $1039-1071$

McDonald K, Higgs G, Iredale R, Tempest V, Gray J (2004) Analysing spatial trends in referral patterns to cancer genetics services: a preliminary investigation of regional variations in Wales. Health Serv Manag Res 17: 263-271

Moley JF, Debenedetti MK, Dilley WG, Tisell LE, Wells SA (1998) Surgical management of patients with persistent or recurrent medullary thyroid cancer. J Int Med 243: 521-526
Moutou C, Le Bihan C, Chompret A, Poisson N, Brugieres L, Bressac B, Feunteun J, Lemerle J, Bonaiti-Pellie C (1996) Genetic transmission of susceptibility to cancer in families of children with soft tissue sarcomas. Cancer 78: $1483-1491$

Muto T, Bussey HJR, Morson BC (1975) The evolution of cancer of the colon and rectum. Cancer 36: 2251-2270

National Cancer Institute (2004) Genetics of Medullary Thyroid Cancer, http://www.nccn.org

National Comprehensive Cancer Network (2004) Genetics/Familial highrisk assessment: breast. http://www.nccn.org

National Health and Medical Research Council (1999a) Clinical Practice Guidelines. Familial aspects of cancer: a guide to clinical practice. ISBN 1864960205

National Health and Medical Research Council (1999b) Guidelines for the prevention, early detection and management of colorectal cancer. Commonwealth of Australia

Neumann HPH, Bausch B, McWhinney SR, Bender BU, Gimm O, Franke G, Schipper J, Kirsch J, Atelhoefer C, Zeres IC, Januszewicz A, Eng C (2002) Germ-line mutations in nonsyndromic phaeochromocytoma. N Engl J Med 346: 1459 - 1466

Neumann HPH, Bender BU, Berger DP, Laubenberger J, Schultze-Seemann W, Wetterauer U, Ferstl FJ, Herbst EW, Schwarzkopf G, Hes FJ, Lips CJ, Lamiell JM, Masek O, Riegler P, Mueller B, Glavac D, Brauch H (1998) Prevalence, morphology and biology of renal cell carcinoma in von Hippel-Lindal disease compared to sporadic renal cell carcinoma. J Urol 1604: $1248-1254$

O’Brien MJ, Winawer SJ, Zauber AG, Gottlieb LS, Sternberg SS, Diaz B, Dickersin GR, Ewing S, Geller S, Kasimian D et al (1990) The National Polyp Study. Patients and polyp characteristics associated with high-grade dysplasia and colorectal adenomas. Gastroenterology 98: $371-379$

Pichert G (2004) Harnessing the potential of cancer genetics in health care. Lancet Oncol 5(10): 626-632

Purdie D, Green A, Bain C, Siskind V, Ward B, Hacker N, Quinn M, Wright G, Russell P, Susil B (1995) Reproductive and other factors and risk of epithelial ovarian cancer: an Australian case-control study. Survey of Women's Health Study Group. Int J Cancer 62: 678-684

Sandles LG, Shulman LP, Elias S, Photopoulos GJ, Smiley LM, Postem WM, Simpson JL (1992) Endometrial adenocarcinoma:genetic analysis suggesting heritable site-specific uterine cancer. Gynaecol Oncol 47: $167-171$

Silverman DT, Schiffman M, Everhart J, Goldstein A, Lillemoe KD, Swanson GM, Schwartz AG, Brown LM, Greenberg RS, Schoenberg JB, Pottern LM, Hoover RN, Fraumeni Jr JF (1999) Diabetes mellitus, other medical conditions and familial history of cancer as risk factors for pancreatic cancer. Br J Cancer 80: $1830-1837$

Slattery ML, Kerber RA (1993) A comprehensive evaluation of family history and breast cancer risk: The Utah population database. JAMA 279: $1563-1568$

Slattery ML, Kerber RA (1994) Family history of cancer and colon cancer risk: the Utah population database. JNCI 86: 1618-1624

Smith RA, Cokkinides V, von Eschenbach AC, Levin B, Cohen C, Runowicz CD, Senes S, Saslow D, Eyre HJ (2002) American Cancer Society Guidelines on testing for early endometrial cancer detection-update 2001. CA cancer J Clin 52: 8-22

St John DJB, McDermott FT, Hopper JL, Debrey EA, Johnson WR, Hughes ES (1993) Cancer risk in relatives of patients with common colorectal cancer. Ann Int Med 118: $785-790$

Trepanier A, Ahrens M, McKinnon W, Peters J, Stopfer J, Campbell Grumet S, Manley S, Culver JO, Acton R, Larsen-Haidle J, Correia LA, Bennett R, Pettersen B, Ferlita TD, Costalas JW, Hunt K, Donlon S, Skryznia C, Farrell C, Callif-Daley F, Vockley CW (2004) Genetic cancer risk assessment and counselling: Recommendations of the National Society of Genetic Counsellors. J Genet Counsel 13: 83-114 